\title{
Consequences of fluid loss in patients treated with ACE inhibitors
}

\author{
J. McMurray and D.M. Matthews
}

The Royal Infirmary, Edinburgh EH3 9YW, UK.

\begin{abstract}
Summary: Three patients are described in whom haemodynamic collapse and acute renal failure occurred following intercurrent gastrointestinal fluid loss during treatment with an angiotensin converting-enzyme inhibitor. The possible consequences of blockade of the formation of angiotensin II during fluid loss are discussed.
\end{abstract}

\section{Introduction}

Angiotensin converting-enzyme (ACE) inhibitors are an important recent addition to the therapeutic armamentarium for the treatment of hypertension and cardiac failure. Recent reviews have forecast their wider use in both conditions. ${ }^{1,2}$ The potentially severe hypotensive effect of these agents in some patients who may be salt and water depleted from concomitant diuretic therapy is well recognized. ${ }^{3}$ Less well known are the consequences of fluid loss from other causes. We report three cases of severe haemodynamic collapse and acute renal failure in patients suffering diarrhoea while taking ACE inhibitors.

\section{Case reports}

\section{Case 1}

A 66 year old man was referred to hospital as an emergency. On arrival he was unconscious, with poor peripheral perfusion and an unrecordable blood pressure. His heart rate was, however, 75/minute. A chest radiograph and electrocardiograph were normal. Laboratory investigations revealed urea $20.4 \mathrm{mmol} / 1$, sodium $137 \mathrm{mmol} / 1$, potassium $5.4 \mathrm{mmol} / 1$, total bicarbonate $20 \mathrm{mmol} / 1$ and glucose $8.3 \mathrm{mmol} / 1$. Haemoglobin was $21.4 \mathrm{~g} / \mathrm{dl}$, haematocrit 0.66 and white cell count $22.4 \times 10^{9} / 1$.

He was treated for acute circulatory failure of

Correspondence: J.McMurray, B.Sc., M.R.C.P., Department of Clinical Pharmacology, Ninewells Hospital and Medical School, Dundee DD1 9SY, UK.

Accepted: 12 November 1986 unknown cause with two units of plasma expander and 8 litres of normal saline intravenously over the next 72 hours and recovered completely. It transpired that the patient had had diarrhoea 10 to 15 times in the 18 hours before presentation; he had also vomited twice before admission. He had been treated for one year, by his general practitioner, with captopril $25 \mathrm{mg}$ twice daily for mild essential hypertension and his blood pressure had been within the normal range for this period. His diarrhoea resolved immediately and stool cultures were negative. Sigmoidoscopy, serum amylase, serum cortisol and cardiac enzymes were normal. Blood chemistry returned to normal and the patient was discharged after 5 days. He remains well on follow-up on captopril $25 \mathrm{mg}$ twice daily.

\section{Case 2}

A 69 year old man, who was an in-patient with manic depression in a psychiatric unit, was transferred for management of a right pneumothorax. He had a history of chronic obstructive airways disease, left pneumothorax, alcohol abuse and had undergone coronary artery bypass grafting 2 years previously. He has been stable for at least 6 months on treatment with captopril $12.5 \mathrm{mg}$ three times daily and bumetanide $1 \mathrm{mg}$ and potassium chloride, two tablets daily, for chronic left ventricular failure. The patient was also taking chlorpromazine $75 \mathrm{mg} /$ day, temazepam and glyceryl trinitrate. Prior to transfer he had been given ampicillin for a chest infection.

A right intercostal drain was inserted with full reexpansion of his lung. Over the next 16 hours, however, the patient developed diarrhoea and vomiting and became hypotensive and oliguric. His systolic blood pressure fell from $165 \mathrm{mmHg}$ on admission to 
$70 \mathrm{mmHg}$. The chest radiograph and electrocardiograph were unchanged. All the patients medications were withheld and, over the next 72 hours, he required 2 units of whole blood, 2 units of plasma and 12 litres of crystalloid to restore extracellular fluid volume and urine output. The patient recovered completely, the blood urea and creatinine falling from $35.1 \mathrm{mmol} / \mathrm{l}$ and $427 \mu \mathrm{mol} / 1$ to $5.7 \mathrm{mmol} / 1$ and $141 \mu \mathrm{mol} / 1$ respectively. No organisms were isolated from stool or blood cultures. A barium enema was normal and a barium meal showed duodenal and jejunal diverticulosis. The diagnosis was felt to be antibiotic-associated colitis. The patient was transferred back to the referring unit.

\section{Case 3}

A 58 year old man was admitted because of nausea, fatigue and postural dizziness. He was known to have longstanding left ventricular dysfunction following mitral valve replacement for rheumatic heart disease. His condition had been stable for two months on treatment with enalapril $20 \mathrm{mg}$ and bumetanide $15 \mathrm{mg}$ daily and his weight had remained steady over this period. For one week before admission he had three to four episodes of diarrhoea daily.

On examination the patient was poorly perfused and had atrial fibrillation and pulse of $56 /$ minute. The venous pressure was low and the blood pressure was $80 / 50 \mathrm{mmHg}$ compared to $120 / 80 \mathrm{mmHg}$ at discharge from a recent admission for introduction of enalapril. A chest radiograph showed cardiomegaly and clear lung fields.

This patient was also felt to be hypovolaemic as a result of gastrointestinal fluid loss aggravated by concurrent treatment with an ACE inhibitor and diuretic. These drugs were withdrawn and 8 litres of intravenous saline administered over the next 72 hours. The patient, however, remained hypotensive and oliguric and his urea and creatinine rose from $35.5 \mathrm{mmol} / \mathrm{l}$ and $452 \mu \mathrm{mol} / 1$ on admission to $41.6 \mathrm{mmol} / 1$ and $637 \mu \mathrm{mol} / 1$ respectively. A diuresis ensued after some days, in keeping with the diagnosis of acute tubular necrosis. The cause of this patient's diarrhoea was not established but it did not recur. Enalapril, and subsequently a diuretic, were cautiously restarted and the patient was finally discharged three weeks after admission on his original medication with a urea of $5.1 \mathrm{mmol} / \mathrm{l}$ and creatinine of $117 \mu \mathrm{mol} / \mathrm{l}$. He remains well on follow-up with normal blood chemistry.

\section{Discussion}

In these three patients taking ACE inhibitors, unexpected salt and water loss, in the form of diarrhoea and vomiting, resulted in life-threatening hypovolaemia, hypotension and renal impairment. The severity in $\stackrel{D}{\perp}$ each case was almost certainly due, in part, to the $\stackrel{\varrho}{c}$ ability of these drugs to interfere with all the important homeostatic responses to such extracellular fluid $\stackrel{\oplus}{\oplus}$ volume loss. ${ }^{4}$ Arterial tone, and thus maintenance of C blood pressure, depends, partly, on the direct vasoconstrictor action of angiotensin II. ${ }^{4,5}$

Autoregulation of intra-renal blood flow, and $\stackrel{\mathbb{Q}}{\varrho}$ therefore glomerular filtration, also depends on angiotensin II. ${ }^{2,6,7}$ These actions are particularly $\vec{\circ}$ important during sodium loss., ${ }^{4,5}$ Two of our patients had cardiac failure which in itself causes reduced renal $\vec{\omega}$ blood flow. In such patients significant hypovolaemia might more quickly produce a critical reduction in renal perfusion and glomerular filtration in the absence of angiotensin II. ${ }^{8}$ These two patients were os $^{\circ}$ also 'primed' by prior diuretic treatment, making them less resistant to additional sodium loss. In the third patient these considerations would not seem to apply $\dot{\infty}_{\infty}$ and it would appear that, even in patients with $\mathcal{N}$

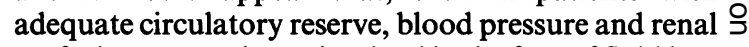
perfusion cannot be maintained in the face of fluid loss without angiotensin II. Because of concurrent treatment with an ACE inhibitor none of these angiotensin II-dependent adaptations to fluid loss could, of $\vec{\emptyset}$ course, occur. Furthermore, enhancement of proxima tubular sodium reabsorption by angiotension II and. stimulation of aldosterone secretion would also have been blocked by these drugs. ${ }^{4}$ Thus two further compensatory responses were certainly attenuated in our patients. Finally, both captopril and enalapril are, to a large extent, renally excreted and renal impairment will result in a vicious cycle further exaggerating these effects. ${ }^{9,10}$ There may be other important, though less well understood, actions of these drugs directly, or indirectly, on the antidiuretic hormone and autonomic-catecholamine responses to the fluid loss. ${ }^{4}$

It is therefore not surprising that an insult such as diarrhoea and vomiting can cause such a profound haemodynamic upset in the presence of pharmacological ACE inhibition, especially in patients with diminished circulatory reserve, as in two of these three cases. This danger, however, does not appear to be well recognized and needs to be stressed. This problem must be anticipated as prompt measures to discontinue these drugs and institute immediate and $\widetilde{\sigma}$ adequate salt and water replacement are necessary to $N$ prevent a potentially very serious outcome.

\section{Acknowledgements}

We would like to thank Dr R.F. Robertson and Dr D. de Bono for permission to report details of patients under their care. All three cases have been reported to the Committee on Safety of Medicines. 


\section{References}

1. Ball, S.G. \& Robertson, J.I.S. A need for new converting enzyme inhibitors? Br Med J 1985, 290: 180-181.

2. Edwards, C.R.W. \& Padfield, P.L. Angiotensin converting enzyme inhibitors: past, present and bright future? Lancet 1985, i: 30-33.

3. Cleland, J.G.F., Dargie, H.J., McAlpine, H., Ball, S.G., Morton, J.J., Robertson, J.I.S. \& Ford, I. Severe hypotension after first dose of enalapril in heart failure. Br Med J 1985, 291: 1309-1312.

4. Reid, I.A. The renin-angiotensin system and body function. Arch Int Med 1985, 145: 1475-1479.

5. Ribeiro, A.B., Kohlman, O., Saragoca, M.A.S., Marson, O. \& Ramos, O.L. The renin angiotensin system in the control of systemic arterial pressure. Drugs 1985, 30 (suppl 1): 6-12.

6. Hall, J.E., Guyton, A.C., Jackson, T.E., Coleman, T.G. Lohmeier, T.E. \& Trippodo, N.C. Control of glomerular filtration rate by renin angiotensin system. Am J Physiol 1977, 233: F366-F372.

7. Blythe, W.B. Captopril and renal autoregulation. $N$ Engl J Med 1983, 308: 390-391.

8. Packer, M., Lee, W.H., Medina, N. \& Yushak, M Influence of renal function on the hemodynamic and clinical responses to long-term captopril therapy in severe chronic heart failure. Ann Int Med 1986, 104: 147-154.

9. Romankiemcz, J.A., Brogden, R.N., Heel, R.C., Speight, T.M. \& Avery, G.S. Captopril: An update review of its pharmacological properties and therapeutic efficacy in congestive heart failure. Drugs 1983, 25: 6-40.

10. Todd,P.A. \& Heel, R.C. Enalapril: A review of its pharmacodynamic and pharmacokinetic properties and therapeutic use in hypertension and congestive heart failure. Drugs 1986, 31: 198-248. 